Yuji Kadoi MD, Shigeru Saito MD, Shinjiro Seki $M D$, M asanobu I de MD, Toshihiro Morita MD, Fumio Goto MD

\title{
Electroconvulsive thera- py impairs systolic performance of the left ventricle
}

Condusion : La performance systolique du ventricule gauche, estimée par l'échocardiographie, a diminué de façon transitoire dans la période suivant immédiatement l'électrochoc.

an echocardiographic automated border detection system.

M ethods: N ine ASA I or II patients scheduled for ECT were studied. Bilateral ECT was performed after the administration of propofol $1 \mathrm{mg} \cdot \mathrm{kg}^{-1}$, succinylcholine $1 \mathrm{mg} \cdot \mathrm{kg}^{-1}$, and assisted mask ventilation with $100 \%$ oxygen. Cardiac function was monitored by transthoracic echocardiography, prior to anesthesia induction and throughout the ECT procedure until ten minutes after the seizure. Results: Increased end-systolic area and decreased fractional area change were observed at one minute after the seizure compared to the awake condition. No regional wall motion abnormalities were observed in all patients both at baseline condition and during the ECT.

Conclusion: Systolic performance of the left ventricle estimated by echocardiography decreased transiently in the immediate period after the electric shock.

O bjectif : Examiner, dans une étude par observation, la performance systolique du ventricule gauche pendant une sismothérapie (ST) en utilisant un système échographique de détection automatisée des limites pariétales.

Méthode : N euf patients ASA I ou II devant subir une TEC ont été étudiés. La TEC bilatérale a été réalisée après l'administration de 1 $\mathrm{mg} \cdot \mathrm{kg}^{-1} \mathrm{de}$ propofol, $1 \mathrm{mg} \cdot \mathrm{kg}^{1} \mathrm{de}$ succinylcholine et la ventilation assistée avec masque et $100 \%$ d'oxygène. La fonction cardiaque a été évaluée par échocardiographie transthoracique, avant l'induction de l'anesthésie et tout au long de la TEC jusqu'à dix minutes après la période convulsive.

R ésultats: L'augmentation de l'aire de fin de systole et la diminution de l'aire fractionnaire ont été observées une minute après la TEC en comparaison avec l'état vigile. Aucune anomalie régionale du mouve ment de la paroi n'a été observée sous les conditions de base et pendant la TEC.

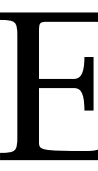

LECTROCONVULSIVE therapy (ECT) is used for treating patients with psychiatric depression. ${ }^{1}$ However, there have been many reports describing cardiac morbidity associated with ECT. ${ }^{1}$ The cardiac morbidity of ECT is due to arrhythmias and instability of arterial blood pressure resulting in myocardial infarction and cardiac arrest. ${ }^{1}$ Therefore, it would be important to assess the cardiac function during ECT.

There are two echocardiographic reports describing the regional wall motion abnormalities (RWMA) during ECT.$^{2-3} \mathrm{H}$ owever, there has been no echocardiographic report describing the time course of cardiac function change during ECT.

Recently, an echocardiographic automated border detection system has been developed, which provides on line, beat-to-beat values of left ventricular cavity area. ${ }^{4}$ These measurements can then be used to estimate load-dependent parameters of systolic performance such as fractional area change or ejection fraction.

The purpose of this study is to assess the time course of left ventricular systolic performance during ECT, using an echocardiographic automated border detection system.

\section{M ethods}

After the approval of our institutional review committee and informed consent, nine ASA I or II patients scheduled for ECT were studied. T wo men and seven women

From the Department of Anesthesiology and Reanimatology, Gunma U niversity, School of M edicine, 3-39-22, Showa-machi, M aebashi, Gunma 371-8511, Japan.

A ddress correspondence to: Dr. Yuji Kadoi, D epartment of Anesthesiology and Reanimatology, Gunma U niversity, School of M edicine, 3-

39-22, Showa-machi, M aebashi, Gunma 371-8511 Japan. Phone:81-272-20-7111; Fax: 81-272-20-8473; E-mail: kadoi@med.gunma-u.ac.jp A ccepted for publication $\mathrm{N}$ ovember 17, 2000. 
were studied (age $51 \pm 8 \mathrm{yr}$; range 15-77, height $156 \pm$ $2 \mathrm{~cm}$; range 149-164, weight $47 \pm 7 \mathrm{~kg}$; range 31-60, values are mean \pm SEM ). All patients received their usual chronic medications (such as antidepressants) in the morning before the ECT. No patient received betaadrenoceptor antagonists, or calcium-channel blocking drugs. All patients received $0.1 \mathrm{mg} \cdot \mathrm{kg}^{-1}$ atropine sulfate im 30 min prior to ECT procedure.

Systolic and diastolic blood pressure, heart rate, arterial oxygen saturation measured by pulse oximeter and ECG were recorded continuously before ECT until the end of the procedure.

After the administration of propofol $1 \mathrm{mg} \cdot \mathrm{kg}^{-1}$ over ten seconds and loss of consciousness, succinylcholine $1 \mathrm{mg} \cdot \mathrm{kg}^{-1}$ was administrated, and assisted mask ventilation with $100 \%$ oxygen. Within two to three minutes after propofol injection, bilateral ECT was performed.

The transthoracic echocardiograph (H ewlett Packard SONOS $5500 \AA, 3.5 \mathrm{MHz}$ transducer, Andover, M A, U SA) used in this study, had automated border detection system (Acoustic Q uantification ${ }^{\circledR}$ system), which could trace the endocardial border continuously, compute the cross-section area of the left ventricular cavity, measure the $R-R$ intervals from the corresponding displayed electrocardiographic tracing. ${ }^{4}$

Left ventricular parasternal short-axis images were recorded at the mid-papillary muscle level for measurements. While viewing the real-time images, the investigator activated automated border detection and adjusted the time gain compensation controls of the ultrasonograph to facilitate the automatic tracking of the highlighted indicator on to the echocardiographic image of the left ventricular endocardial border. U sing the track ball of the ultrasonograph, the investigator outlined a region of interest that contained the left ventricular cavity throughout the cardiac cycle, excluding other cardiac chambers. The areas of left ventricle (LV) were then calculated from each cardiac cycle and displayed in a waveform. All studies were performed by the same operator (Y.K.) to eliminate interobserver variability and improve reproducibility. To minimize intraobserver variability, we recorded the acoustic quantification on video tape and re-assessed the validity of the gain setting. As all patients in this study were lean, we could observe LV cavity clearly in all cases.

The following left ventricular indexes were measured for each patient: (1) end-systolic area (ESA), (2) end- diastolic area (EDA), (3) fractional area change $(F A C) ; F A C=(E D A-E S A) / E D A X 100$.

According to Mulier et al., ${ }^{6}$ we used the quotient of systolic blood pressure and (EDA-ESA) as an index of left ventricular afterload. $D$ ata are expressed as means $\pm \mathrm{SEM}$.

After confirmation of equal variance among the group by the Bartlett test, changes in the variables were compared with analysis of variance for repeated measures with a $P$ value $<0.05$ considered statistically significant. Post-hoc testing was performed using Scheffe's test.

\section{Results}

There were no significant differences in EDA, heart rate and the quotient of systolic blood pressure and (EDA- ESA) (Table). Increased ESA and decreased FAC were observed at one minute after the electrical shock compared to the awake condition. Systolic blood pressure was increased from one to four minutes after the electrical shock, compared to the awake condition. Diastolic blood pressure was increased from one to three minutes after the electrical shock, compared to the awake condition.

The Figure shows the relationship between the changes in FAC and systolic blood pressure. There was a relative correlation between the changes in FAC and

TABLE Time course for changes of hemodynamic variables

\begin{tabular}{lllllllll}
\hline M easurement time & $(1)$ & $(2)$ & $(3)$ & $(4)$ & (5) & (6) & (7) & (8) \\
\hline End-diastolic area $\left(\mathrm{cm}^{2}\right)$ & $7.5 \pm 0.8$ & $7.8 \pm 0.8$ & $9.3 \pm 0.9$ & $8.2 \pm 0.7$ & $8.4 \pm 0.9$ & $8.8 \pm 0.6$ & $8.9 \pm 0.8$ & $7.8 \pm 0.7$ \\
Endsystolic area $\left(\mathrm{cm}^{2}\right)$ & $3.1 \pm 0.3$ & $3.5 \pm 0.4$ & $5.5 \pm 0.6^{*}$ & $4.7 \pm 0.4$ & $4.1 \pm 0.6$ & $4.0 \pm 0.4$ & $3.7 \pm 0.4$ & $3.4 \pm 0.4$ \\
Fractional area change (\%) & $58 \pm 5$ & $55 \pm 4$ & $44 \pm 4^{*}$ & $49 \pm 5$ & $52 \pm 5$ & $56 \pm 4$ & $60 \pm 5$ & $56 \pm 4$ \\
H eart rate (beat:min) & $92 \pm 5$ & $91 \pm 6$ & $106 \pm 7$ & $104 \pm 7$ & $99 \pm 5$ & $97 \pm 4$ & $96 \pm 5$ & $97 \pm 4$ \\
Systolic BP (mmH g) & $112 \pm 4$ & $108 \pm 4$ & $147 \pm 10^{*}$ & $145 \pm 6^{*}$ & $144 \pm 7^{*}$ & $137 \pm 6^{*}$ & $131 \pm 6$ & $121 \pm 4$ \\
Diastolic BP (mmH g) & $61 \pm 4$ & $63 \pm 3$ & $81 \pm 8^{*}$ & $87 \pm 8^{*}$ & $80 \pm 8^{*}$ & $80 \pm 5$ & $73 \pm 4$ & $65 \pm 3$ \\
Systolic BP / ED A-ESA & $47 \pm 17$ & $48 \pm 10$ & $62 \pm 11$ & $57 \pm 9$ & $57 \pm 11$ & $55 \pm 17$ & $49 \pm 13$ & $48 \pm 12$ \\
\hline
\end{tabular}

Values are mean \pm SEM

EDA=end-diastolic area, $E S A=$ end-systolic area, $\mathrm{HR}=$ heart rate, $\mathrm{BP}=$ blood pressure

(1), awake; (2), one minute after the propofol administration; (3), one minute after electrical shock; (4), two minutes after electrical shock; (5), three minutes after electrical shock; (6), four minutes after electrical shock; (7), five minutes after elecrical shock; (8), ten minutes after electrical shock

$* \mathrm{P}<0.05$ compared to period (1) 


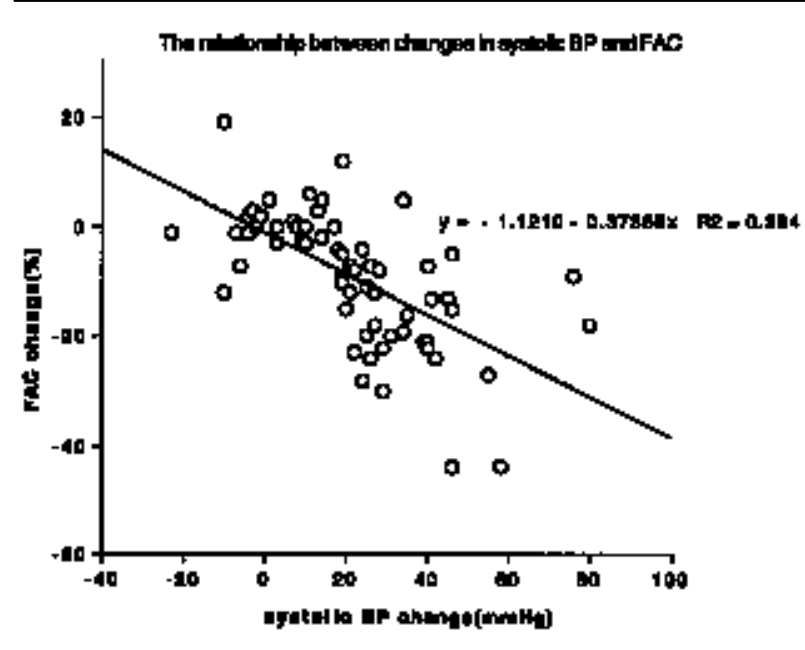

FI G U RE The Figure shows the relationship between the changes in fractional area change (FAC) and systolic blood pressure (BP). There was a relative correlation between the changes in FAC and systolic BP $\left(r^{2}=0.384\right)$.

systolic blood pressure $\left(r^{2}=0.384\right)$. N o RWMA or ST segment changes were observed in all patients both at baseline condition and during the ECT procedure.

\section{Discussion}

This decreased systolic performance observed in this study might be attributable to sympathetic hyperactivity which induces tachycardia, an increase in systemic vascular resistance and hypertension at this period. ECT provokes a rise in plasma catecholamines, and induces a considerable increase in myocardial oxygen demand. ${ }^{1}$ This increased myocardial oxygen demand is likely to increase the risk of myocardial ischemia in patients with coronary artery disease. The decreased systolic performance observed in the present study might worsen with myocardial ischemia after ECT.

In this study we used propofol at a dose of $1 \mathrm{mg} \cdot \mathrm{kg}^{-1}$ as a hypnotic drug. Fredman et al..$^{5}$ reported that propofol at a dose of $0.75 \mathrm{mg} \cdot \mathrm{kg}^{-1}$ improved hemodynamic stability after ECT. In contrast, Mulier et al. ${ }^{6}$ reported that propofol at a dose of $1.4 \mathrm{mg} \cdot \mathrm{kg}^{-1}$ reduced systolic arterial blood pressure mainly through its negative inotropic properties. This discrepancy might be attributable to the difference in a propofol dose and in premedical drugs such as beta-adrenoceptor antagonists or atropine. ${ }^{7}$

The decrease in FAC observed at one minute after the ECT would be derived from two mechanisms. Both administration of propofol at a dose of $1 \mathrm{mg} \cdot \mathrm{kg}^{-1}$ and increased systolic blood pressure shown in the Figure could induce a decrease in myocardial contractility.
There have been two reports describing RWMA during ECT. M essina et al. ${ }^{2}$ reported a $45 \%$ incidence of new RWMA immediately after ECT. In contrast, $O$ 'Connor et al. ${ }^{3}$ reported that new RWM A were seen in only one of $26(4 \%)$ ECT sessions. They also reported that patients without RWM A at baseline had no new RWMA after ECT. In the present study, we did not examine all segments of the $L V$ because we focussed on systolic performance during ECT. H owever, we could not detect any RWM A in the section we observed. This partial result is consistent with 0 'Connor's report. A more extensive study will be necessary to determine whether new RWM A could be observed after ECT.

Although we realize that automated border detection system might underestimate or overestimate EDA and ESA, an echocardiographic automated border detection system is a promising non-invasive assessment of cardiac performance. ${ }^{8}$ And, many investigators have also observed that accurate, real time measures of left ventricular area dimension can be obtained with echocardiographic automated border detection system. ${ }^{9}$

In summary, we found that systolic performance of the LV, estimated by echocardiography is decreased transiently in the immediate period after ECT.

\section{References}

1 Selvin BL. Electroconvulsive therapy- 1987. Anesthesiology 1987; 67: 367-85.

2 M essina A G, Paranicas M, Katz B, M arkowitz J, Y ao F$S, D$ evereux R B. Effect of electroconvulsive therapy on the electrocardiogram and echocardiogram. Anesth Analg 1992; 75: 511-4.

3 O'C onnor CJ, R othenberg DM, Soble JS, et al. The effect of esmolol pretreatment on the incidence of regional wall motion abnormalities during electroconvulsive therapy. Anesth Analg 1996; 82: 143-7.

4 Bednarz JE, M arcus R H, Lang R M. Technical guidelines for performing automated border detection studies. J Am Soc Echocardiogr 1995; 8: 293-305.

5 Fredman B, d'Etienne J, Smith I, H usain M M, White PF. Anesthesia for electroconvulsive therapy: effects of propofol and methohexital on seizure activity and recovery. Anesth Analg 1994; 79: 75-9.

6 Mulier JP, Wouters PF, Van A ken H, Vermaut G, Vandermersch $E$. Cardiodynamic effects of propofol in comparison with thiopental: assessment with a transesophageal echocardiographic approach. Anesth Analg 1991; 72: 28-35.

7 Mayur PM, Shree R S, Gangadhar BN, Subbakrishna DK, Janakiramaiah N, R ao GSU. Atropine premedication and the cardiovascular response to electroconvul- 
sive therapy. Br J Anaesth 1998; 81: 466-7.

8 Cahalan M K, I onescu P, M elton HE, A dler S, Kee LL, Schiller N B. Automated real-time analysis of intraoperative transesophageal echocardiograms. Anesthesiology 1993; 78: 477-85.

$9 \mathrm{H}$ ille $\mathrm{Z}$, Thys D. M onitoring left ventricular performance. In: O moto R, O ka Y (Eds). Transesophageal Echocardiography. Tokyo: Shindan-to-Chiryo Co., Ltd, 2000: 57-70. 